\title{
Four polypore species new to Himachal Pradesh
}

\author{
Ramandeep Kaur, Avneet Pal Singh* and Gurpaul Singh Dhingra \\ Department of Botany, Punjabi University, Patiala 147002, Punjab, India \\ *Corresponding authorEmail: avneetbot@gmail.com \\ (Submitted on March 13,2020; Accepted on June 15, 2020)
}

\begin{abstract}
Four species of the polyporoid fungi, namely Ceriporia viridans (Berk. \& Br.) Donk, Gloeophyllum carbonarium (Berk. \& M.A. Curtis) Ryvarden, Grammothele fuligo (Berk. \& Broome) Ryvarden and Trametes suaveolens (L.) Fr. are described as new to Himachal Pradesh on the basis of specimens specimens collected from different parts of district Sirmaur of Himachal Pradesh. Genus Grammothele is recorded for the first time from Himachal Pradesh.
\end{abstract}

Key words: Polyporaceae, polypores, poroid hymenium, hyphal system

\section{INTRODUCTION}

Polypores, a heterogenous assemblage of wood decaying fungi, are peculiar in having macroscopic fructifications with unilateral hymenium organized at the interior of tubes with open end forming the pores. These fructifications are variable with respect to their nature, habit and morphology. Polypores possess monomitic, dimitic or trimitic hyphal system with thin- to slightly thick-walled, usually hyaline or rarely coloured generative hyphae with or without clamp connections. Ancillary structures such as cystidia, cystidioles or setae may or may not be present. The basidiospores range from cylindrical to allantoid to ellipsoid, thin- to thick-walled, subhyaline to yellowish brown or brown and may or may not be stained in Melzer's reagent or cotton blue. As per the current classification system majority of these fungi are placed under orders Polyporales and Hymenochaetales of class Agaricomycetes of sub phylum Agaricomycotina in phylum Basidiomycota (MycoBank, 2020). These fungi form an efficient group of wood decayers in a forest ecosystem and are reported to cause white and brown rot of both soft and hardwoods. During the collection tours conducted in the Rajgarh, Paonta Sahib and Shillai areas of Sirmaur district of Himachal Pradesh some interesting polypore specimens were collected. Based on the morphological details these were identified as Ceriporia viridans (Berk. \& Br.) Donk, Gloeophyllum carbonarium (Berk. \& M.A. Curtis) Ryvarden, Grammothele fuligo (Berk. \& Broome) Ryvarden and Trametes suaveolens (L.) Fr. All the four species described and illustrated presently are new records for the state of Himachal Pradesh. The genus Grammothele is recorded for the first time from the study area. The specimens of the species described are deposited at the Herbarium, Department of Botany, Punjabi University, Patiala (PUN). The color standards used are after Kornerup and Wanscher (1978).

\section{TAXONOMIC DESCRIPTIONS}

1. Ceriporia viridans (Berk. \& Br.) Donk, Med. Bot. Mus. Univ. Utrecht 9: 171, 1933.

- Polyporus viridians Berk. \& Br., Ann. Mag. Nat. Hist. 3 (7): 379, 1861.

Figs. 1-5

Carpophore annual, resupinate, effused, adnate, up to $2 \mathrm{~mm}$ thick in cross section; hymenial side poroid, cream to yellowish white to orange when fresh, becoming grayish orange to

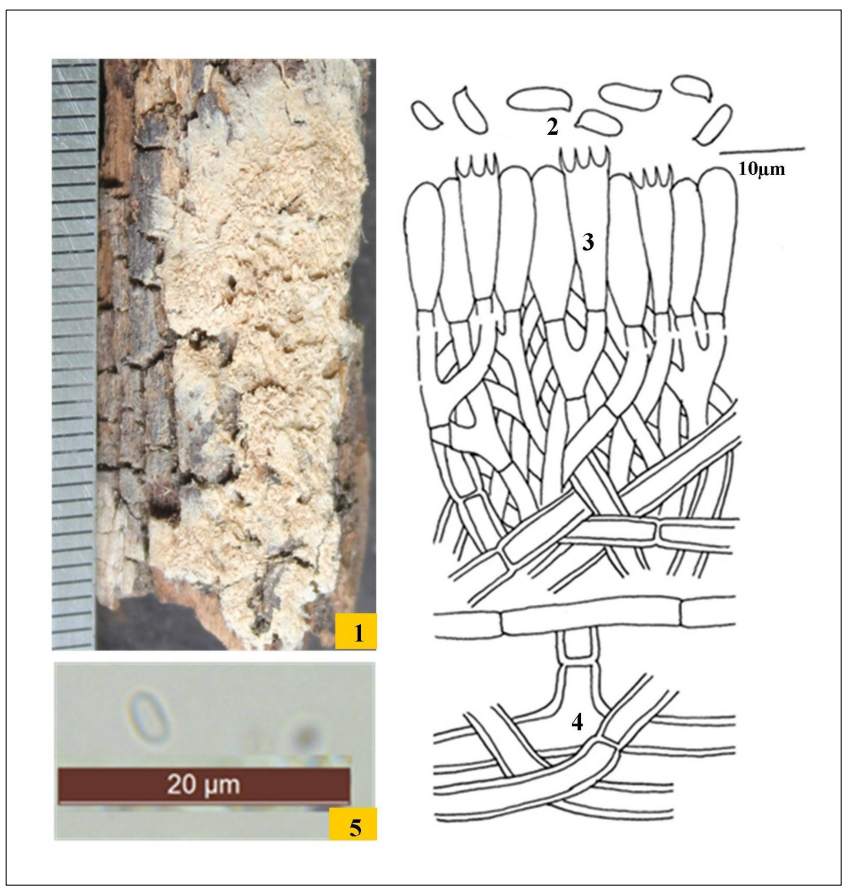

Figs. 1-5. Ceriporia viridians: 1. Carpophore showing hymenial side; 2-4. Line diagrams showing 2. basidiospores, 3 . basidia and 4 . generative hyphae; 5 . Photomicrograph showing a basidiospore.

brownish orange on drying; pores angular, 4-5 per mm; dissepiments up to $160 \mu \mathrm{m}$ thick, entire; pore tubes up to $1 \mathrm{~mm}$ long, yellowish white; subiculum up to $1 \mathrm{~mm}$ thick, homogeneous, soft, yellowish white; margins fibrillose, paler to concolorous.

Hyphal system monomitic. Generative hyphae septate, without clamps, up to $4.9 \mu \mathrm{m}$ wide, branched, thin- to thickwalled. Cystidial elements absent. Basidia clavate to subclavate, $14.5-16 \times 3.7-4.3 \mu \mathrm{m}$, four sterigmate, without basal clamp; sterigmata up to $3.1 \mu \mathrm{m}$ long. Basidiospores cylindrical to suballantoid, 4.3-6.8 $\times 1.4-3.1 \mu \mathrm{m}$, smooth, thinwalled, gives negative reaction with Melzer's Reagent as well as Cotton Blue.

Specimen studied- Himachal Pradesh: Sirmaur, Rajgarh, on stump of Pinus roxburghii, Ramandeep and Avneet 10797 (PUN), September 12, 2016. 
Remarks- The presently described species is close to Ceriporia alachuana, from which it differs in having slightly wider basidiospores. Earlier C. viridans was reported from India by Sharma $(2000,2012)$ from Meghalaya, Uttarakhand and West Bengal and Ranadive (2013) from Maharashtra.

2. Gloeophyllum carbonarium (Berk. \& M.A. Curtis) Ryvarden, Mycotaxon 20 (2): 334, 1984.

- Hexagonia carbonaria Berk. \& M.A. Curtis, Grevillea 1 (5): 68, 1872.

Figs.6-11

Carpophores annual, effused, reflexed to pileate, solitary to imbricate, soft; pilei up to $6 \times 1.3 \times 0.5 \mathrm{~cm}$, applanate, fuse laterally, tough to coriaceous; abhymenial side tomentose to velutinate, azonate, grayish brown to brown when fresh, no prominent change on drying; hymenial side poroid brownish orange to light brown when fresh, light brown to dark brown on drying; pores angular to hexagonal, 1-2 per $\mathrm{mm}$; dissepiments $80 \mu \mathrm{m}$ wide ; context dark brown, up to $2 \mathrm{~mm}$ thick; pore tubes dark brown, up to $3 \mathrm{~mm}$ deep; margins acute to obtuse, irregular to wavy, fertile, concolorous to indeterminate.

Hyphal system dimitic. Generative hyphae subhyaline, septate, with clamps, up to $4.5 \mu \mathrm{m}$ wide, branched, thinwalled. Skeletal hyphae yellowish brown to brown, up to 5.6 $\mu \mathrm{m}$ wide, rarely branched, thick-walled. Context formed of loosely interwoven generative and skeletal hyphae running

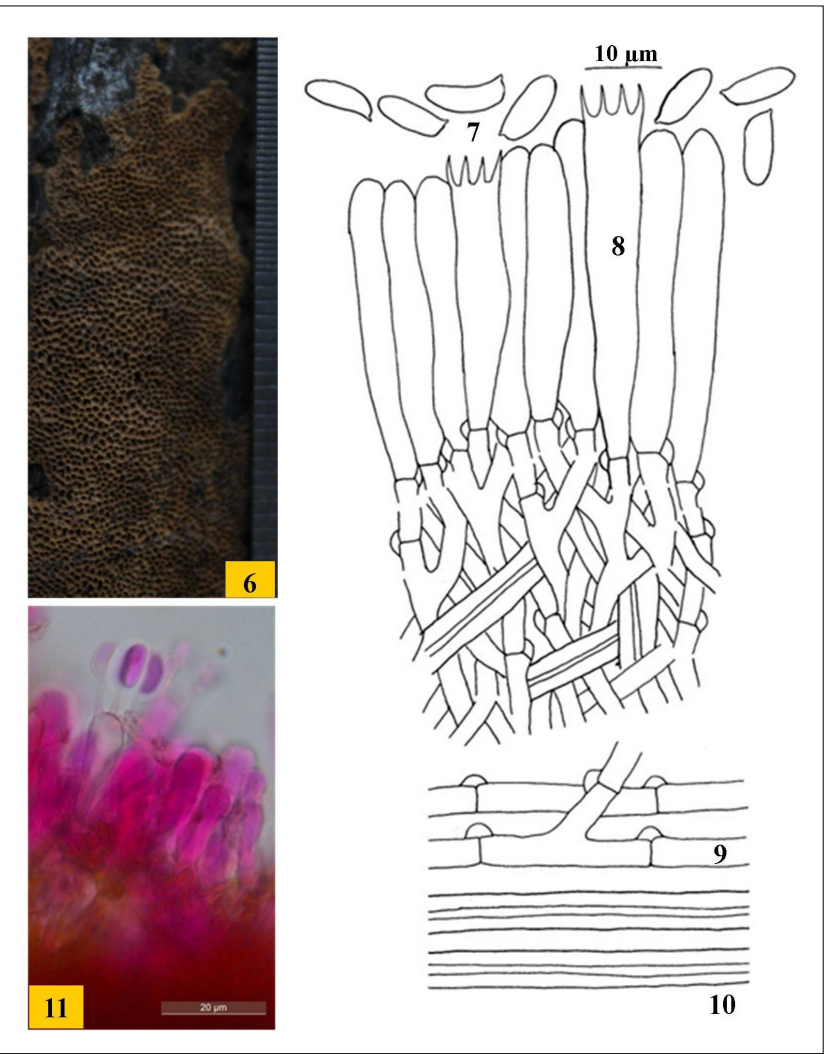

Figs. 6-11. Gloeophyllum carbonarium: 6. Carpophore showing hymenial side; 7-10. Line diagrams showing 7. basidiospores, 8 . basidia, 9. generative hyphae and 10 . skeletal hyphae; 11. Photomicrograph showing basidia with basidiospores. parallel to the substrate; tramal region compact, formed of generative and skeletal hyphae; subhymenial region usually formed by generative hyphae developing at right angles to the trama. Cystidia absent. Basidia narrowly clavate to subcylindrical, 30-44 $\times$ 5.5-7.5 $\mu \mathrm{m}$, four sterigmate, with basal clamp; sterigmata up to $4.7 \mu \mathrm{m}$ long. Basidiospores ellipsoid to subcylindrical to suballantoid, 8-10.5 $\times 3.5-4.5$ $\mu \mathrm{m}$, smooth, thin-walled.

Specimen studied- Himachal Pradesh: Sirmaur, Rajgarh, Mantali, on the stump of Pinus roxburghii, Ramandeep and Avneet 10798 (PUN).

Remarks- $G$. carbonarium is unique in having soft basidiocarps with larger, angular to hexagonal pores and dimitic hyphal system. From India it was earlier reported from Uttarakhand by Sharma (2012).

3. Grammothele fuligo (Berk. \& Broome) Ryvarden, Transactions of the British Mycological Society 73: 15, 1979.

- Polyporus fuligo Berk. \& Broome, Botanical Journal of the Linnean Society 14: 53, 1875.

Figs.12-18

Carpophore annual, resupinate, effused, adnate, up to $290 \mu \mathrm{m}$ thick in cross section; hymenial side poroid, violet white to grayish violet when fresh, no prominent change on drying; pores angular, 5-6 per mm; dissepiments up to $55 \mu \mathrm{m}$ wide, entire; subiculum up to $165 \mu \mathrm{m}$ wide, violet grey; pore tubes up to $125 \mu \mathrm{m}$ deep; tramal tissue concolorous with the hymenial side; margins fibrillose, paler than the colour of the
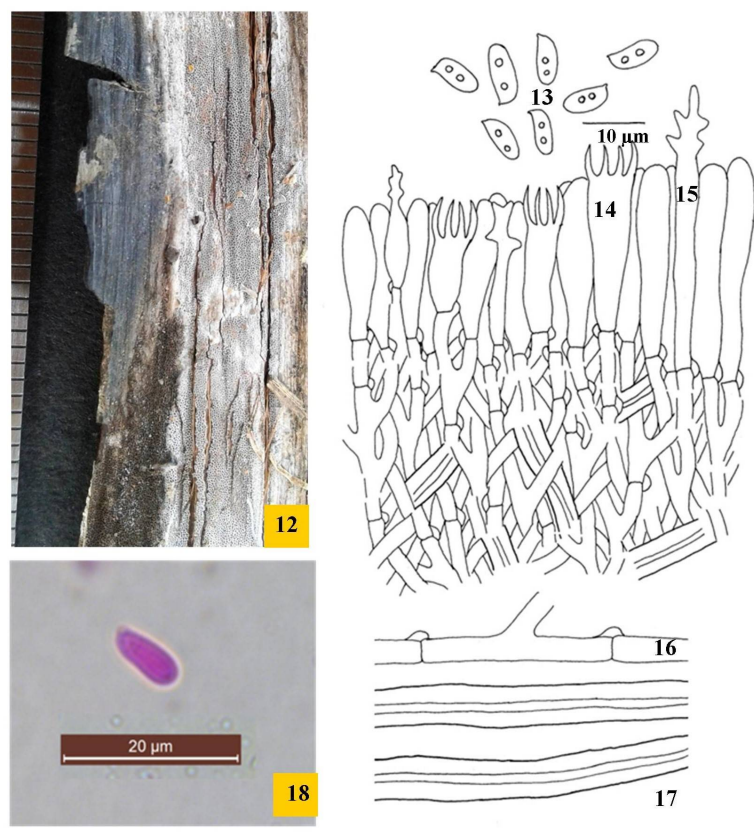

Figs. 12-18. Grammothele fuligo: 12. Carpophore showing hymenial side; 13-17. Line diagrams showing 13. basidiospores, 14. basidia, 15. denrohyphidia, 16. generative hyphae and 17 . skeletal hyphae; 18. Photomicrograph showing a basidiospore. 
hymenial side, occasionally indeterminate.

Hyphal system dimitic. Generative hyphae septate, with clamps, up to $3.2 \mu \mathrm{m}$ wide, branched, thin-walled. Skeletal hyphae aseptate, up to $5.1 \mu \mathrm{m}$ wide, thick-walled, unbranched, dextrinoid. Both generative and skeletal hyphae intertwined, parallel to substrate, loosely interwoven in the context and at right angles to the substrate, compact in the trama. Hymenium restricted to the base of the pores. Dendrohyphidia present along the pore edges, irregularly branched at the apex, 14-20 × 1.8-3.2 $\mu \mathrm{m}$. Cystidia absent. Basidia clavate, 13-18 $\times$ 5.6-7.9 $\mu \mathrm{m}$, four sterigmate, with basal clamp; sterigmata up to $9.4 \mu \mathrm{m}$ long. Basidiospores subcylindrical to subellipsoid, 5.6-9.4 × 1.8-3.2 $\mu \mathrm{m}$, smooth, thin-walled, with oily contents.

Specimen studied- Himachal Pradesh: Sirmaur, Paonta Sahib, near Gurudwara Sahib, on the trunk of Phoenix dactylifera, Ramandeep 10799 (PUN), October 6, 2015.

Remarks- The presently described species is characterized by the presence of violet white to grayish hymenial surface, dimitic hyphal system, clamped generative hyphae and subcylindrical to subellipsoid basidiospores. It is being described for the first time from the state of Himachal Pradesh. Formerly from India it was reported by Bakshi (1971) as Poria ravenalae from West Bengal, Natarajan and Kolandvelu (1998) as Programme ravenalae from Tamil Nadu, Sharma (2012) as Grammothele fuligo from West Bengal, Ranadive et al. (2011) and Ranadive (2013) as Grammothele fuligo from Maharashtra.

4. Trametes suaveolens (L.) Fr., Epicrisis Systematis Mycologici: 491, 1838.

- Boletus suaveolens L., Species Plantarum: 1177, 1753. Figs. 19-25

Carpophore annual, with pleasant anise smell, pileate, sessile, solitary to imbricate; pilei up to $13.5 \times 8 \times 1 \mathrm{~cm}$, dimidiate, tough; abhymenial side tomentose to glabrous, weakly zonate to azonate, yellowish white to light orange to pinkish white to grayish white when fresh, no prominent change on drying; hymenial side poroid, yellowish white to light orange to pinkish white when fresh, no prominent change on drying; pores round to angular, 1-3 per mm, splitting up with age; dissepiments up to $70 \mu \mathrm{m}$ wide, entire; context homogenous, up to $0.9 \mathrm{~cm}$ thick, concolorous with abhymenial side; pore tubes up to $0.1 \mathrm{~cm}$ deep, whitish; margins obtuse, regular, sterile up to $2 \mathrm{~mm}$, concolorous with hymenial side.

Hyphal system trimitic. Generative hyphae subhyaline, septate, with clamps, up to $3.7 \mu \mathrm{m}$ wide, branched, thinwalled. Skeletal hyphae subhyaline, aseptate, up to $4.9 \mu \mathrm{m}$ wide, occasionally branched, thick-walled. Binding hyphae subhyaline, aseptate, up to $4.9 \mu \mathrm{m}$ wide, much branched, thick-walled. Cystidial elements absent. Basidia clavate to sinuous, $19-22 \times 5.5-6.2 \mu \mathrm{m}$, four sterigmate, with basal clamp; sterigmata up to $3.1 \mu \mathrm{m}$ long. Basidiospores cylindrical to sub ellipsoid, 5.5-9.9 $\times 3.3-3.7 \mu \mathrm{m}$, smooth, thin-walled, reaction with Melzer's Reagent and Cotton Blue negative.

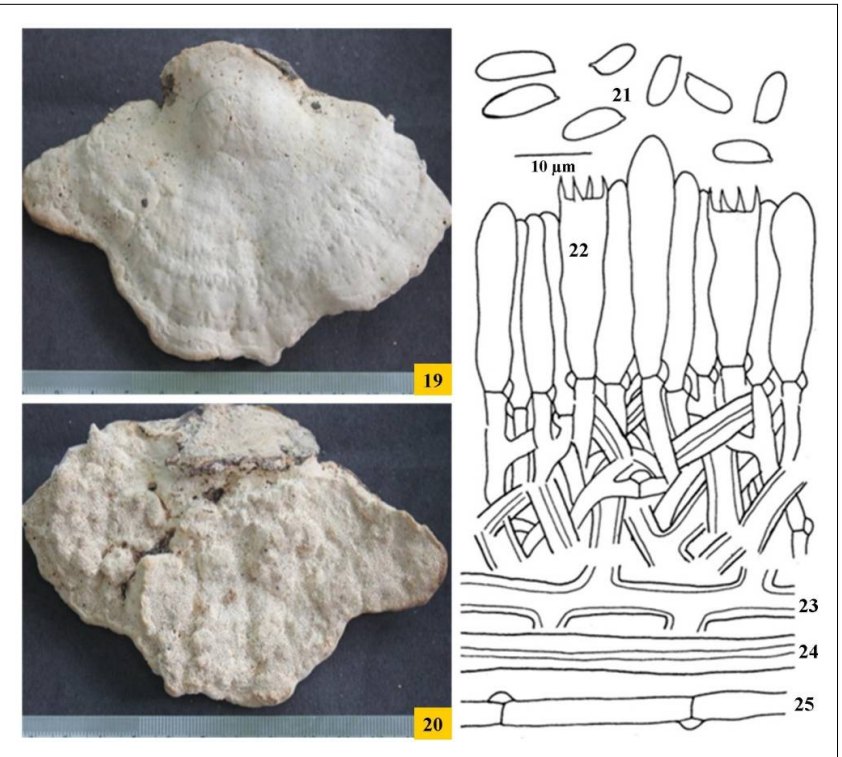

Figs. 19-25. Trametes suaveolens: 19-20. Carpophore showing 19. abhymenial side and 20. hymenial side; 21-25. Line diagrams showing outline of 21. basidiospores, 22 . basidia, 23. binding hyphae, 24. skeletal hyphae and 25 . generative hyphae.

Sample studied-Himachal Pradesh: Sirmaur, Shillai, Kando, on the stump of Cedrus deodara, Ramandeep 10800 (PUN), September 3, 2017.

Remarks- This species differs from rest of the species within this genus in having pleasant anise smell. Earlier from India it was reported from Uttarakhand (Bakshi, 1971; Sharma, 2000; 2012) and Maharashtra (Ranadive et al., 2011; Ranadive, 2013).

\section{ACKNOWLEDGEMENTS}

The authors are grateful to Head, Department of Botany, Punjabi University, Patiala for providing the requisite research facilities. The authors also acknowledge the financial assistance provided by University Grants Commission, New Delhi under SAP DSA Phase I programme.

\section{REFERENCES}

Bakshi, B.K. 1971. Indian Polyporaceae (on trees and timber). Indian Council of Agricultural Research, New Delhi. 246 pp.

Kornerup, A. and Wanscher, J.H. 1978. Methuen Handbook of colours, $3^{\text {rd }}$ ed. Methuen and Co. Ltd. London. 252 pp.

MycoBank. 2020. Fungal databases. Nomenclature and species banks. [Accessed: 18/4/2020].

Natarajan, K. and Kolandavelu, K. 1998. Resupinate Aphyllophorales of Tamil Nadu, India. Centre for Advanced Study in Botany, University of Madras, Chennai, 133 pp.

Ranadive, K.R. 2013. An overview of Aphyllophorales (wood rotting fungi) from India. International 
Journal of Current Microbiology and Applied Sciences 2 (12): 112-139.

Ranadive, K.R., Vaidya, J.G., Jite, P.K., Ranade, V.D., Bhosale, S.R., Rabba, A.S., Hakimi, M., Deshpande, G.S., Rathod, M.M., Forutan, A., Kaur, M., NaikVaidya, C.D., Bapat, G.S. and Lamrood, P. 2011. Checklist of Aphyllophorales from the Western Ghats of Maharashtra State, India. Mycosphere 2 (2): 91-114.
Sharma, J.R. 2000. Genera of Indian Polypores. Botanical Survey of India, Ministry of Environment and Forest, Calcutta. 188 pp.

Sharma, J.R. 2012. Aphyllophorales of Himalaya. Botanical Survey of India, Ministry of Environment and Forests, Calcutta, 590 pp. 